\title{
Sepsis-induced Innate and Adaptive Immune Suppression
}

\author{
Jennifer A. Muszynski ${ }^{1,2,3}$ and Mark W. Hall*,1,2,3 \\ ${ }^{I}$ The Department of Pediatrics, Section of Critical Care Medicine, The Ohio State University College of Medicine; \\ ${ }^{2}$ Nationwide Children's Hospital; ${ }^{3}$ The Research Institute at Nationwide Children's Hospital
}

\begin{abstract}
The inflammatory response to sepsis has classically been characterized by an overactive innate immune response. Recent adult and pediatric evidence suggests that the immune response is quite dynamic in this setting, often with endogenous innate and adaptive immunosuppression following the onset of sepsis. Sepsis-induced innate immune dysfunction can include reduction in antigen presenting capacity (as evidenced by decreased monocyte HLA-DR expression) and low pro-inflammatory cytokine production capacity (as evidenced by reduced ex vivo LPS-induced tumor necrosis factor- $\alpha$ production). The term immunoparalysis describes a state of severe reduction in these parameters and has been associated with increased risks for the development of nosocomial infection and death in septic adults and children. Intriguing evidence suggests that immunoparalysis may be reversible with beneficial effects on outcomes. Adaptive immune dysfunction has also been reported following the onset of sepsis. Lymphopenia, lymphocyte apoptosis, and skewing toward anti-inflammatory $\mathrm{T}$ cell subtypes (such as regulatory $\mathrm{T}$ cells) have all been associated with adverse outcomes from sepsis. Without specific testing, most aspects of sepsis-related immune dysfunction are occult. Accordingly, the development of robust immune monitoring and modulation protocols should be a high priority in the battle to improve outcomes from sepsis in critically ill adults and children.
\end{abstract}

Keywords: Immune, innate, adaptive, sepsis, immunoparalysis, suppression.

\section{INTRODUCTION}

It was classically thought that sepsis represents an overactivation of the immune system with exaggerated release of pro-inflammatory cytokines such as interleukin (IL) - $1 \beta$ and tumor necrosis factor (TNF)- $\alpha$. Indeed, the signs and symptoms which define sepsis typically result not from the infection itself, but from the systemic immune response to that infection. To this end, multiple attempts have been made to treat sepsis by decreasing the magnitude of this response through the targeting and neutralization of specific proinflammatory mediators [1-7]. Unfortunately, despite promising results in animal models these trials have largely failed to improve outcomes in septic patients. The disparity between the human and animal data may be partly attributable to the fact that humans increasingly survive the initial pro-inflammatory phase of septic disease, with many instances of sepsis-related mortality occurring later in the context of multiple organ failure and secondary infection [8, 9]. We now know that the natural history of sepsis in the era of intensive care medicine involves a dynamic immunologic state influenced by both pro- and anti-inflammatory forces (Fig. 1). Cytokines such as IL-10 and transforming growth factor (TGF)- $\beta$, both potently anti-inflammatory, likely play as important a role in the pathophysiology of sepsis as their pro-inflammatory counterparts (Table 1). This review will focus on the compensatory anti-inflammatory response syndrome (CARS) in sepsis including its

*Address correspondence to this author at the Critical Care Medicine, Nationwide Children's Hospital, 700 Children's Drive, Columbus, OH 43205, USA; Tel: (614) 722 - 3438; Fax: (614) 722 - 3443;

E-mail: Mark.Hall@NationwideChildrens.org quantification and associations with adverse outcomes and will address the innate and adaptive arms of the immune system in turn.

\section{SEPSIS-INDUCED INNATE IMMUNE SUPPRESSION}

The bulk of the initial work done to investigate the immunobiology of sepsis centered on the cells and mediators of the innate immune system [10-13]. Innate immune cells are the first cellular responders to invading organisms and are therefore vital to host defense. Cell types including monocytes (and their mature form, tissue macrophages), dendritic cells, and neutrophils recognize pathogens through constitutively expressed receptors including toll-like receptors (TLR) and receptors for the Fc portion of immunoglobulin. Once stimulated, these cells should rapidly and robustly produce pro-inflammatory cytokines. In addition, innate immune cells should be able to recognize and ingest pathogens as well as process and present antigens to members of the adaptive immune system. Monocytes, for example, present antigens on cell-surface major histocompatibility complex (MHC) class II molecules such as human leukocyte antigen (HLA)-DR.

Measurement of monocyte HLA-DR expression was among the first ways that the anti-inflammatory response in critical illness was quantified in the laboratory $[10,11,14]$. To measure HLA-DR expression, blood samples are stained with fluorochrome-tagged antibodies against CD14 (a monocyte cell surface marker) and HLA-DR. Using flow cytometry, the fluorescence of the monocyte anti-HLA-DR antibody can be compared to a negative isotype control. The percentage of monocytes strongly expressing $H L A-D R$ can therefore be quantified. Volk et al. described monocyte 


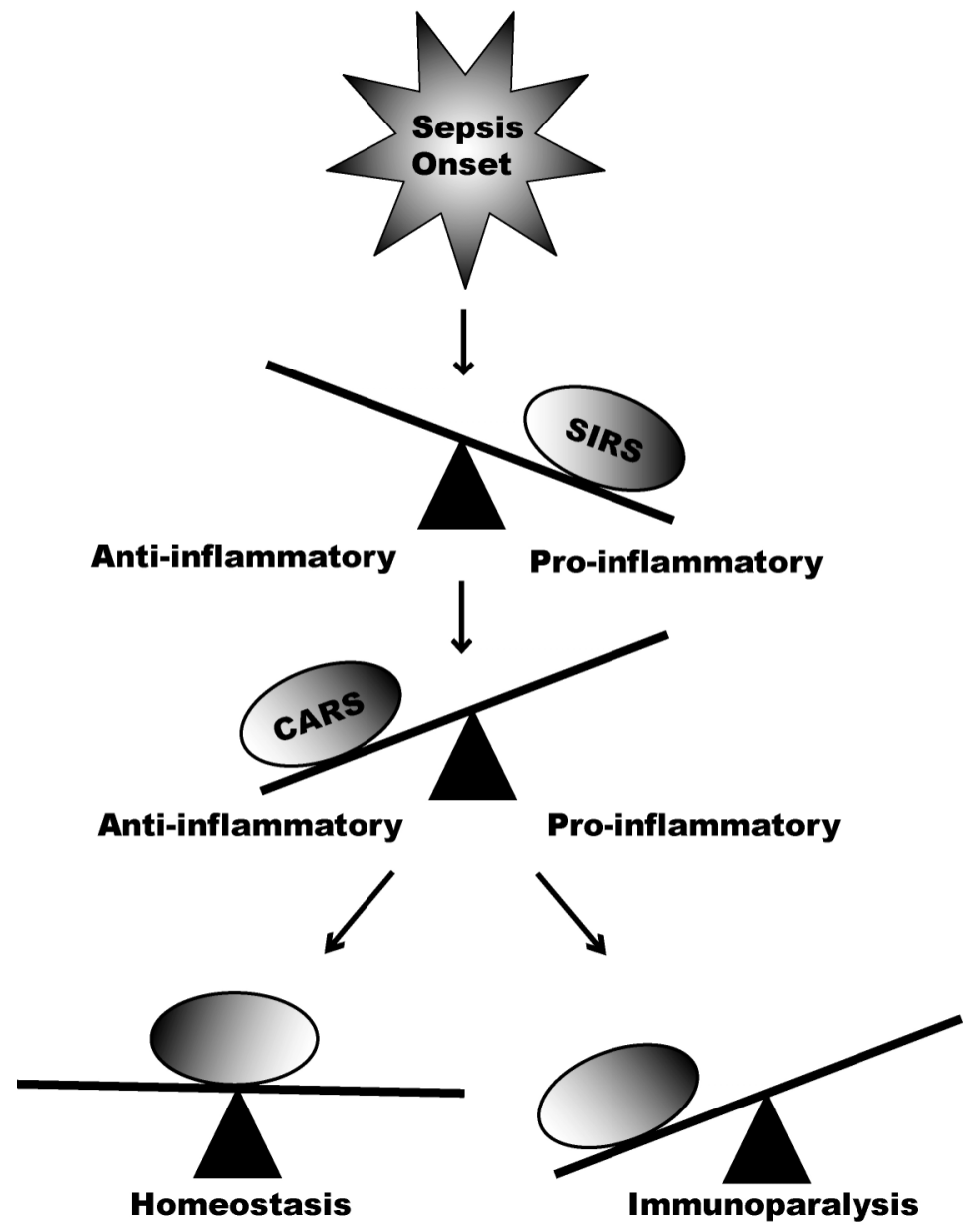

Fig. (1). The dynamic inflammatory response to sepsis. At the onset of sepsis, patients experience a pro-inflammatory surge known as the systemic inflammatory response syndrome (SIRS). This is typically followed, in a matter of hours, by a compensatory anti-inflammatory response syndrome (CARS), characterized by hyporesponsiveness of the innate immune response. In the subsequent hours to days, the patient should achieve a state of immunological homeostasis. In some patients, however, a prolonged anti-inflammatory phenotype persists. This is known as immunoparalysis.

HLA-DR expression in several cohorts of adults with sepsis and other forms of critical illness in the 1990s [13, 15, 16]. His group showed that monocyte HLA-DR expression was downregulated following the onset of a pro-inflammatory insult, but that mild or transient downregulation was not associated with adverse outcomes. Only patients whose monocyte HLA-DR expression fell below 30\% for more than 5 days were at increased risk for death [13]. This degree of severe innate immune dysfunction has been termed "immunoparalysis". More recently, Monneret et al. showed in 86 adult patients with sepsis that persistently low HLADR expression $(<30 \%)$ at Day 3-4 of illness was independently associated with increased mortality (OR 6.5; $95 \%$ CI 1.6-26) [8]. Similarly, in a study of 20 septic adults Abe et al. demonstrated decreased monocyte HLA-DR expression on Day 3 of illness in nonsurvivors $(44 \%$ in nonsurvivors, $72 \%$ in survivors, $92 \%$ in healthy controls; $p$ $<0.05)$ [17].

Alternatively, innate immune function can be measured by quantifying the potential of whole blood to produce proinflammatory cytokines when stimulated ex vivo with lipopolysaccharide (LPS). Whole blood containing normal innate immune cells will produce high levels of TNF $\alpha$ when co-incubated with LPS. Adaptive immune cells, lacking the TLR-4 receptor for LPS, likely contribute little to this acute ex vivo cytokine response. This capacity to produce $\mathrm{TNF} \alpha$ upon ex vivo stimulation of whole blood with LPS has been shown to be reduced in the hours and days following proinflammatory stimuli such as sepsis, trauma, and cardiopulmonary bypass in adults and children [18-22]. We have recently shown that the depth and duration of this drop in pro-inflammatory capacity is related to mortality from pediatric multiple organ dysfunction syndrome (MODS) [23].

Unfortunately, standardization of ex vivo stimulation techniques has been lacking in the field. There are, therefore, no universally accepted thresholds for definition of immunoparalysis by this method. For example, in our laboratory with our reagents and our sample processing technique a TNF $\alpha$ production threshold of $<200 \mathrm{pg} / \mathrm{ml}$ predicts adverse outcomes. Another laboratory using a different type of LPS or incubation procedure may find a different cutoff. The need to develop highly standardized measures of innate immune function is urgent, given the fact that it is not possible to detect immunoparalysis through typical screening laboratory values such as complete blood 
Table 1. Characteristics of the Pro- and Anti-Inflammatory Immune Responses to Sepsis

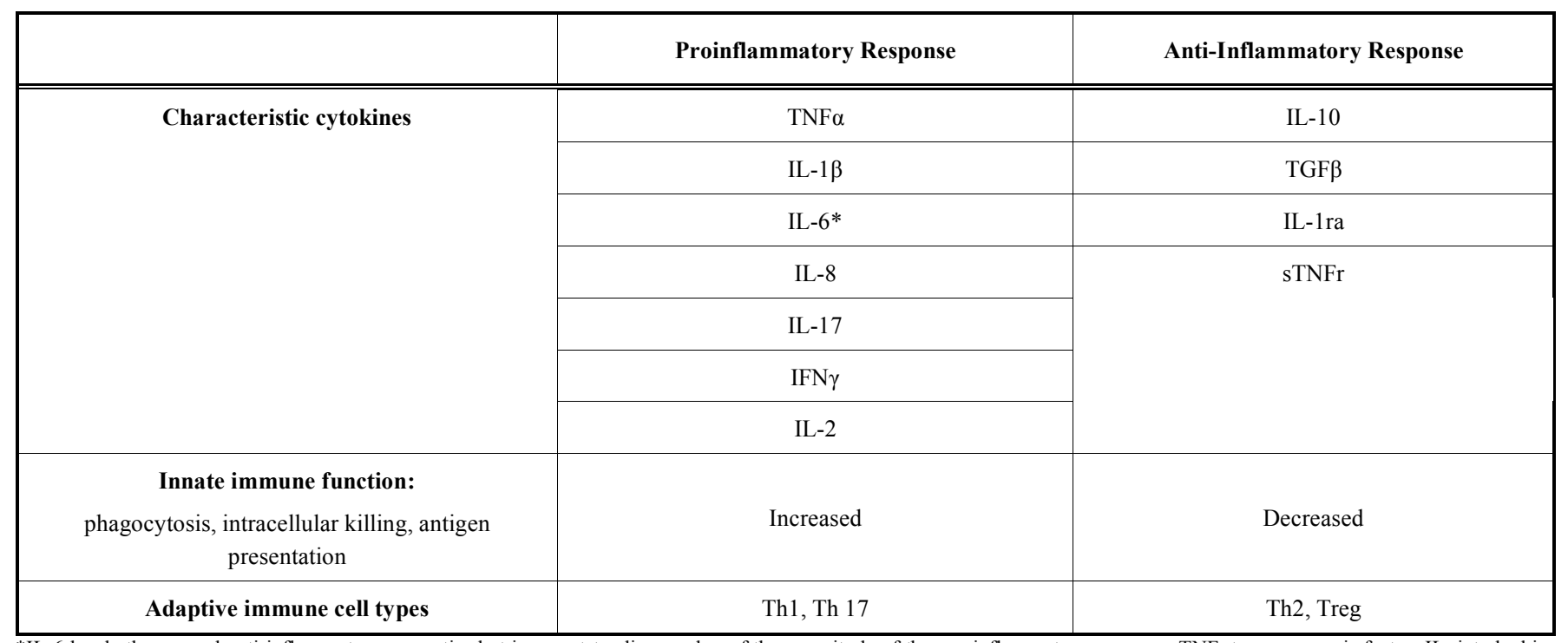

*IL-6 has both pro- and anti-inflammatory properties but is an outstanding marker of the magnitude of the pro-inflammatory response. TNF: tumor necrosis factor, IL: interleukin, TGF: transforming growth factor, IL-1ra: IL-1 receptor antagonist, sTNFr: soluble TNF receptor, IFN: interferon, Th: helper T cell, Treg: regulatory T cell

counts. The variability in currently reported ex vivo stimulation procedures makes it difficult to identify thresholds for potential interventions.

Similarly, measurements of monocyte HLA-DR expression may vary based on laboratory techniques including time from blood sampling to antibody staining, the type of anticoagulant used, individual flow cytometer settings, and variations between lots of fluorochromes [24]. Recently, Döcke et al. described the use of a technique whereby HLA-DR expression from patient samples is compared to manufacturer-provided standards such that the number of HLA-DR molecules per monocyte can be calculated. With this method, variations attributable to flow cytometers and settings were minimized, though interlaboratory differences continued to exist due to inconsistent pre-analytic processing and handling of specimens [25]. Clearly, additional work needs to be done to promote uniformity in the diagnosis of sepsis-induced innate immune suppression.

\section{EVIDENCE FOR THE REVERSIBILITY OF SEPSIS- INDUCED INNATE IMMUNE SUPPRESSION}

Mounting in vitro and in vivo evidence suggests that immunoparalysis is reversible. Fumeaux et al. were able to induce immunoparalysis in healthy donor monocytes by incubating them with plasma from septic patients. The resultant reduction in HLA-DR expression was significantly improved by the addition of a neutralizing antibody against IL-10 (an anti-inflammatory cytokine) to the cell culture media [26]. Several small case series have suggested that the administration of an immunostimulatory drug can reverse innate immune dysfunction in critically ill adults. Döcke et $a l$. gave interferon (IFN)- $\gamma$ to nine adults with sepsis-induced immunoparalysis and demonstrated normalization of monocyte HLA-DR expression and ex vivo LPS-induced $\mathrm{TNF} \alpha$ production capacity following treatment [22]. Nierhaus et al. showed similar results using granulocyte macrophage colony-stimulating factor (GM-CSF) [27]. In both case series mortality was improved compared to historical controls. In 2005 Rosenbloom et al. performed the first randomized controlled trial of GM-CSF in the setting of adult sepsis [28]. They demonstrated in 33 patients that GMCSF administration was associated with improved monocyte HLA-DR expression and more rapid resolution of infection compared to placebo. In the pediatric population, Bilgin et al. demonstrated a $20 \%$ reduction in mortality in a 60 -patient randomized controlled trial of GM-CSF for the treatment of sepsis in neutropenic neonates [29]. These latter two trials are notable for the fact that they did not employ a priori measurements of innate immune function at the time of enrollment and randomization (with the exception of the neutrophil count in the Bilgin study). It is possible that targeted immunostimulatory therapies aimed at patients with reduced monocyte HLA-DR expression and/or ex vivo LPSinduced $\mathrm{TNF} \alpha$ production may produce more striking results. Accordingly, Meisel et al. recently conducted a prospective, randomized, placebo-controlled clinical trial of GM-CSF in 38 adults with sepsis-induced immunoparalysis, in which severe reduction in monocyte HLA-DR expression was a study entry criterion [30]. In this study, GM-CSF therapy resulted in rapid normalization of monocyte HLA-DR expression and ex vivo LPS-induced TNF $\alpha$ production capacity compared to controls. This restoration of innate immune function was associated with reduced durations of mechanical ventilation in the GM-CSF-treated subjects.

\section{SEPSIS-INDUCED ADAPTIVE IMMUNE SUPPRES- SION}

The adaptive immune system is comprised of lymphocytes. In contrast to innate immunity, the adaptive immune system promotes the development of highly pathogen-specific effector cells that respond to discrete antigens. Lymphocytes usually rely on members of the innate immune system for antigen processing and 
presentation, without which cells of the adaptive immune system typically cannot become activated. Once activated, B lymphocytes mature into antibody secreting plasma cells. Meanwhile, $\mathrm{T}$ lymphocytes are grouped by cell surface marker expression into families that perform a variety of biological functions. While $\mathrm{CD} 8+$ (cytotoxic) $\mathrm{T}$ cells are responsible for directly killing infected cells, CD4+ (helper) $\mathrm{T}$ cells produce cytokines to direct the development and activation of other parts of the immune system. These processes are characterized by the development of immunologic memory, such that the response to the first exposure to a particular antigen is slower and less robust than subsequent exposures. In the setting of sepsis, therefore, the adaptive immune system is thought of as being important for the modulation of the subacute phase of illness, exerting its effects on the order of days after sepsis onset, rather than hours.

CD4+ $\mathrm{T}$ cells are notable for their immunomodulatory role and they have traditionally been divided into subgroups of T-helper (Th) cells based on their cytokine release profiles. Th1 cells secrete pro-inflammatory cytokines such as IFN $\gamma$ while $\mathrm{Th} 2$ cells produce anti-inflammatory cytokines such as IL-10 and IL-4 which skew the immune response toward antibody production and away from cellmediated killing. Th17 cells are a recently elucidated proinflammatory subset of helper $\mathrm{T}$ cells. They are identified by the production of IL-17 and IL-22, seem to play an important role in autoimmune pathology, and may contribute to the overall pro-inflammatory adaptive immune phenotype in other illness states as well [31].

\section{REGULATORY T CELLS}

A fourth family of $\mathrm{CD} 4+\mathrm{T}$ cells are the regulatory $\mathrm{T}$ cells (Treg). This group of cells has the ability to profoundly suppress both the innate and adaptive immune responses by virtue of anti-inflammatory cytokine production and direct, cell contact-mediated inhibition. Among these, "naturally occurring" regulatory $\mathrm{T}$ cells develop in the thymus and represent about $5-10 \%$ of the circulating $\mathrm{T}$ lymphocyte pool in normal individuals. They play an important role in protecting against autoimmunity by suppressing the response to self antigens [32, 33]. Naturally occurring Tregs highly express the cell surface marker CD25, though activated $\mathrm{T}$ cells express some CD25 as well which may hinder the recognition of these cells in vivo [34]. FoxP3 is a transcription factor important in the development and suppressive activity of naturally occurring Tregs and may aid in their identification [35]. Recently, downregulation of the expression of CD127 (the IL-7 receptor) has also been used to distinguish naturally occurring regulatory $\mathrm{T}$ cells from other lymphocytes. CD127 expression negatively correlates with FoxP3, and low expression of CD127 has been found to correlate more closely with suppressive activity than that of CD25 [36, 37].

In addition to naturally occurring regulatory $\mathrm{T}$ cells, there exist at least two subsets of CD4+ "inducible" regulatory $\mathrm{T}$ cells. These cells are CD25 and FoxP3 negative and have no known specific cell surface markers. While inducible Tregs have been generated in vitro under certain culture conditions, their presence in vivo can only be inferred through their ability to produce massive amounts of anti-inflammatory cytokines when stimulated. For example, Tr1 cells produce IL-10 [38-41] and Th3 cells produce TGF- $\beta$ [42], both in far greater quantities than can be accounted for by $\mathrm{Th} 2$ cells alone.

\section{SEPSIS-INDUCED LYMPHOCYTE APOPTOSIS}

Several animal studies have demonstrated decreased numbers of lymphocytes and increased lymphocyte apoptosis in response to sepsis [43-47]. Reversal of lymphocyte apoptosis has resulted in improved survival in these models. In 2001, Hotchkiss et al. showed reduced numbers of splenic and circulating $\mathrm{B}$ and $\mathrm{T}$ lymphocytes in adult critically ill patients with sepsis compared to non-septic critically ill patients and trauma patients [48]. These and other data have implicated apoptosis as the source of lymphocyte loss [49]. A subsequent study of 52 adults demonstrated more lymphocyte apoptosis in patients with septic shock compared to controls on Day 1 of illness. In this study, survivors had an increase in lymphocyte count by Day 6, while nonsurvivors continued to have lymphopenia [50]. A similar effect has been seen in children with multiple organ failure. In a study of 113 critically ill pediatric patients, prolonged lymphopenia (an absolute lymphocyte count $<1000$ cells $/ \mathrm{mm}^{3}$ for $>7$ days) was associated with dramatically increased odds of secondary infection and death [51]. Taken together, these data suggest that lymphopenia represents an important form of adaptive immune suppression in the setting of sepsis, though mechanisms responsible for lymphocyte apoptosis in sepsis remain incompletely understood.

\section{REGULATORY T CELLS AND SEPSIS}

Several animal studies have demonstrated increased percentages of $\mathrm{CD} 4{ }^{+} \mathrm{CD} 25^{+}$Tregs in the setting of sepsis, though data on their impact on outcomes in these models are conflicting. In a study of mice subjected to cecal ligation and puncture (CLP) to induce polymicrobial sepsis, the proportion of $\mathrm{CD} 4+\mathrm{T}$ cells expressing markers of naturally occurring regulatory $\mathrm{T}$ cells was increased compared to control mice [52]. Further, CD4+CD25+ cells taken from septic mice suppressed proliferation of non-regulatory $\mathrm{T}$ cells in ex vivo assays to a greater extent when compared to Tregs from non-septic mice. Interestingly, depletion of CD4+CD25+ Tregs did not alter mortality in these animals. Similarly, Wisnoski et al. in 2007 showed an increase in CD25+ Tregs in mice following CLP [53]. In this study, CD4+ cells from septic mice showed decreased proliferation upon ex vivo stimulation which was restored by pretreatment with anti-CD25 antibodies to deplete the Treg population. Mortality from CLP was again unaffected by Treg depletion. In contrast, Heuer et al. demonstrated an increased survival and improved bacterial clearance when mice were treated with stimulated Treg cells either before or 6 hours after CLP [54]. Conversely, Scumpia et al. showed that blocking the glucocorticoid-induced TNF receptor (GITR), an intervention which should reduce Treg-mediated suppression, prior to CLP increased $\mathrm{T}$ cell proliferative capacity as well as pro-inflammatory Th1 cytokine release and improved mortality [55]. Reasons for these differences are unclear. One potential confounder is the use of antiCD25 antibodies for Treg depletion. Because some activated 
Table 2. Common Immune Phenotypes Following Sepsis

\begin{tabular}{|c|c|c|c|}
\hline & Normal & CARS & Severe Immune Suppression \\
\hline \hline Monocyte HLA-DR expression & $>95 \%$ & $30-95 \%$ & $<30 \%$ \\
\hline $\begin{array}{c}\text { Whole blood ex vivo LPS- } \\
\text { stimulated TNF } \alpha \text { production } \\
\text { capacity }\end{array}$ & +++ & ++ & + \\
\hline Plasma IL-10 & ND & + & ++ \\
\hline Lymphocyte count & +++ & ++ & + \\
\hline Treg percentage & + & ++ & +++ \\
\hline
\end{tabular}

ND: Not detectable.

T cells also express CD25 it is possible that some activated effector $\mathrm{T}$ cells were affected by Treg depletion.

Regulatory $\mathrm{T}$ cells have been studied in septic humans as well. In a cohort of 16 adults with septic shock, naturally occurring Tregs were increased compared to other $\mathrm{CD}^{+} \mathrm{T}$ cells in the setting of sepsis-induced immunoparalysis [56]. Specifically, nonsurvivors showed elevated percentages of $\mathrm{CD} 4{ }^{+} \mathrm{CD} 25^{+}$Tregs 7-10 days after the onset of septic shock compared to survivors. A subsequent study of 54 adult patients showed a significant increase in naturally occurring Tregs at Days 1-2 and Days 3-6 following onset of septic shock in the context of a marked decrease in total CD4+ count and CD4+CD25- effector T cells compared to healthy controls [57]. In other words, the Treg population appeared to remain robust while other $\mathrm{T}$ cells disappeared from the circulation. Similarly, a study of 19 adult trauma patients demonstrated decreased numbers of total CD4+ cells with an increase in percentage of CD4+CD25+ Tregs by Day 7 post injury [58]. Tregs isolated from injured patients showed increased suppressive activity, produced less IFN $\gamma$ (proinflammatory) and more IL-4, IL-5, and IL-10 (antiinflammatory) upon ex vivo stimulation than Tregs taken from healthy controls. In these patients, ex vivo production of IL-10 and IL-4 by CD4+ T cells isolated on Day 1 of injury was associated with the subsequent development of sepsis.

These data suggest that sepsis or trauma may result in an increase in the relative number and suppressive activity of regulatory $\mathrm{T}$ cells. Mechanisms underlying this augmented Treg response are not well understood. One possibility is that regulatory $\mathrm{T}$ cells may be less susceptible to sepsis-induced apoptosis or that they may recover more quickly. There is some evidence to suggest that regulatory $\mathrm{T}$ cells are less susceptible to dexamethasone-induced lymphocyte apoptosis and $\mathrm{T}$ cell receptor-mediated cell death [59, 60]. Perhaps, regulatory $\mathrm{T}$ cells respond differently to apoptotic signals compared to effector $\mathrm{T}$ cells in a septic environment.

Little is known about the relationship between innate and adaptive immune suppression in septic patients. In the Monneret study, innate immune function as determined by monocyte HLA-DR expression was markedly reduced by the first day following disease onset [8]. Survivors began recovering HLA-DR expression by day 7-10, while nonsurvivors, who had an increased percentage of naturally occurring Treg cells by this time, did not. One could hypothesize that a Treg-dominant adaptive immune response may serve to perpetuate the immunoparalyzed phenotype, though this interplay is speculative at this time.

\section{CONCLUSION}

There are undoubtedly septic patients who suffer morbidity and mortality as the result of an uncontrolled proinflammatory response. We are learning, however, that many patients are dying in the setting of an anti-inflammatory immune phenotype. These phenotypes (summarized in Table 2) can be quantified through relatively easy laboratory measurements, though these tests have not yet found their way into standard practice at most U. S. institutions in some part due to a lack of assay standardization.

Nonetheless, without these assays immunoparalysis is likely to remain occult, despite the availability of promising therapies for its reversal. To that end, further work to define immune monitoring and immunomodulatory regimens targeting high-risk septic patients is urgently needed to promote immunologic balance in both the innate and adaptive immune systems.

\section{REFERENCES}

[1] Fisher CJ, Jr., Dhainaut JF, Opal SM, et al. Recombinant human interleukin 1 receptor antagonist in the treatment of patients with sepsis syndrome. Results from a randomized, double-blind, placebo-controlled trial. Phase III rhIL-1ra Sepsis Syndrome Study Group. JAMA 1994; 15: 271: 1836-43.

[2] Fisher CJ, Jr., Opal SM, Dhainaut JF, et al. Influence of an antitumor necrosis factor monoclonal antibody on cytokine levels in patients with sepsis. The CB0006 sepsis syndrome study group. Crit Care Med 1993; 21:318-27.

[3] Opal SM, Fisher CJ, Jr., Dhainaut JF, et al. Confirmatory interleukin-1 receptor antagonist trial in severe sepsis: a phase III, randomized, double-blind, placebo-controlled, multicenter trial. The interleukin-1 receptor antagonist sepsis investigator group. Crit Care Med 1997; 25: 1115-24.

[4] Abraham E, Anzueto A, Gutierrez G, et al. Double-blind randomised controlled trial of monoclonal antibody to human tumour necrosis factor in treatment of septic shock. NORASEPT II study group. Lancet 1998; 351: 929-33.

[5] Abraham E, Wunderink R, Silverman H, et al. Efficacy and safety of monoclonal antibody to human tumor necrosis factor alpha in patients with sepsis syndrome. A randomized, controlled, doubleblind, multicenter clinical trial. TNF-alpha MAb Sepsis study group. JAMA 1995; 273: 934-41.

[6] Cohen J, Carlet J. INTERSEPT: an international, multicenter, placebo-controlled trial of monoclonal antibody to human tumor 
necrosis factor-alpha in patients with sepsis. International sepsis trial study group. Crit Care Med 1996; 24: 1431-40.

[7] Fein AM, Bernard GR, Criner GJ, et al. Treatment of severe systemic inflammatory response syndrome and sepsis with a novel bradykinin antagonist, deltibant (CP-0127). Results of a randomized, double-blind, placebo-controlled trial. CP-0127 SIRS and sepsis study group. JAMA 1997; 277: 482-7.

[8] Monneret G, Lepape A, Voirin N, et al. Persisting low monocyte human leukocyte antigen-DR expression predicts mortality in septic shock. Intensive Care Med 2006; 32: 1175-83.

[9] Leclerc F, Leteurtre S, Duhamel A, et al. Cumulative influence of organ dysfunctions and septic state on mortality of critically ill children. Am J Respir Crit Care Med 2005; 171: 348-53.

[10] Polk HC, Jr., Wellhausen SR, Regan M. A systematic study of host defense processes in badly injured patients. Ann Surg 1986; 204 : 282-97.

[11] Cheadle WG, Hershman MJ, Wellhausen SR, Polk HC, Jr. HLADR antigen expression on peripheral blood monocytes correlates with surgical infection. Am J Surg 1991; 161: 639-45.

[12] Cheadle WG, Mercer-Jones M, Heinzelmann M, Polk HC, Jr. Sepsis and septic complications in the surgical patient: who is at risk? Shock 1996; 6 (Suppl 1): S6-9.

[13] Volk HD, Reinke P, Krausch D, et al. Monocyte deactivation-rationale for a new therapeutic strategy in sepsis. Intensive Care Med 1996; 22 (Suppl 4): S474-81.

[14] Hershman MJ, Cheadle WG, Wellhausen SR, Davidson PF, Polk HC, Jr. Monocyte HLA-DR antigen expression characterizes clinical outcome in the trauma patient. Br J Surg 1990; 77: 204-7.

[15] Reinke P, Volk HD. Diagnostic and predictive value of an immune monitoring program for complications after kidney transplantation. Urol Int 1992; 49: 69-75.

[16] Volk HD, Reinke P, Docke WD. Immunological monitoring of the inflammatory process: Which variables? When to assess? Eur J Surg Suppl. 1999; 584:70-2

[17] Abe R, Hirasawa H, Oda S, et al. Up-Regulation of Interleukin-10 mRNA expression in peripheral leukocytes predicts poor outcome and diminished human leukocyte antigen-dr expression on monocytes in septic patients. J Surg Res 2008; 147: 1-8.

[18] Allen ML, Hoschtitzky JA, Peters MJ, et al. Interleukin-10 and its role in clinical immunoparalysis following pediatric cardiac surgery. Crit Care Med 2006; 34: 2658-65.

[19] Flohe S, Lendemans S, Schade FU, Kreuzfelder E, Waydhas C. Influence of surgical intervention in the immune response of severely injured patients. Intensive Care Med 2004; 30: 96-102.

[20] Heagy W, Nieman K, Hansen C, Cohen M, Danielson D, West MA. Lower levels of whole blood LPS-stimulated cytokine release are associated with poorer clinical outcomes in surgical ICU patients. Surg Infect 2003; 4: 171-80.

[21] Majetschak M, Flach R, Kreuzfelder E, et al. The extent of traumatic damage determines a graded depression of the endotoxin responsiveness of peripheral blood mononuclear cells from patients with blunt injuries. Crit Care Med 1999; 27: 313-8.

[22] Docke WD, Randow F, Syrbe U, et al. Monocyte deactivation in septic patients: restoration by IFN-gamma treatment. Nat Med 1997; 3: 678-81.

[23] Hall MW, Gavrilin MA, Knatz NL, Duncan MD, Fernandez SA, Wewers MD. Monocyte mRNA Phenotype and adverse outcomes from pediatric multiple organ dysfunction syndrome. Pediatr Res 2007; 62: 597-603.

[24] Monneret G, Elmenkouri N, Bohe J, et al. Analytical requirements for measuring monocytic human lymphocyte antigen DR by flow cytometry: application to the monitoring of patients with septic shock. Clin Chem 2002; 48: 1589-92.

[25] Docke WD, Hoflich C, Davis KA, et al. Monitoring temporary immunodepression by flow cytometric measurement of monocytic HLA-DR expression: a multicenter standardized study. Clin Chem 2005; 51: 2341-7.

[26] Fumeaux T, Pugin J. Role of interleukin-10 in the intracellular sequestration of human leukocyte antigen-DR in monocytes during septic shock. Am J Respir Crit Care Med 2002; 166: 1475-82.

[27] Nierhaus A, Montag B, Timmler N, et al. Reversal of immunoparalysis by recombinant human granulocyte-macrophage colony-stimulating factor in patients with severe sepsis. Intensive Care Med 2003; 29: 646-51.

[28] Rosenbloom AJ, Linden PK, Dorrance A, Penkosky N, CohenMelamed $\mathrm{MH}$, Pinsky MR. Effect of granulocyte-monocyte colony-stimulating factor therapy on leukocyte function and clearance of serious infection in nonneutropenic patients. Chest 2005; 127: 2139-50.

[29] Bilgin K, Yaramis A, Haspolat K, Tas MA, Gunbey S, Derman O. A randomized trial of granulocyte-macrophage colony-stimulating factor in neonates with sepsis and neutropenia. Pediatrics 2001; 107: 36-41.

[30] Meisel C, Schefold JC, Pschowski R, et al. GM-CSF to Reverse Sepsis-associated Immunosuppression: a Double-blind Randomized Placebo-controlled Multicenter Trial. Am J Respir Crit Care Med 2009; 180: 640-8.

[31] Ouyang W, Kolls JK, Zheng Y. The biological functions of T helper 17 cell effector cytokines in inflammation. Immunity 2008 ; 28: 454-67.

[32] Jonuleit H, Schmitt E. The regulatory T cell family: distinct subsets and their interrelations. J Immunol 2003; 171: 6323-7.

[33] Venet F, Chung CS, Monneret G, et al. Regulatory T cell populations in sepsis and trauma. J Leukoc Biol 2008; 83: 523-35.

[34] Pillai V, Ortega SB, Wang CK, Karandikar NJ. Transient regulatory T-cells: a state attained by all activated human T-cells Clin Immunol 2007; 123: 18-29.

[35] Campbell DJ, Ziegler SF. FOXP3 modifies the phenotypic and functional properties of regulatory $T$ cells. Nat Rev 2007; 7: 30510 .

[36] Liu W, Putnam AL, Xu-Yu Z, et al. CD127 expression inversely correlates with FoxP3 and suppressive function of human CD4+ T reg cells. J Exp Med 2006; 203: 1701-11.

[37] Seddiki N, Santner-Nanan B, Martinson J, et al. Expression of interleukin (IL)-2 and IL-7 receptors discriminates between human regulatory and activated T cells. J Exp Med 2006; 203: 1693-700.

[38] Battaglia M, Gregori S, Bacchetta R, Roncarolo MG. Tr1 cells: from discovery to their clinical application. Semin Immunol 2006; 18: $120-7$.

[39] Cottrez F, Hurst SD, Coffman RL, Groux H. T regulatory cells 1 inhibit a Th2-specific response in vivo. J Immunol 2000; 165: 4848-53.

[40] Roncarolo MG, Gregori S, Battaglia M, Bacchetta R, Fleischhauer $\mathrm{K}$, Levings MK. Interleukin-10-secreting type 1 regulatory $\mathrm{T}$ cells in rodents and humans. Immunol Rev 2006; 212: 28-50.

[41] Groux H, O'Garra A, Bigler M, et al. A CD4+ T-cell subset inhibits antigen-specific T-cell responses and prevents colitis. Nature 1997; 389: $737-42$.

[42] Chen Y, Kuchroo VK, Inobe J, Hafler DA, Weiner HL. Regulatory $\mathrm{T}$ cell clones induced by oral tolerance: suppression of autoimmune encephalomyelitis. Science 1994; 265: 1237-40.

[43] Bommhardt U, Chang KC, Swanson PE, et al. Akt decreases lymphocyte apoptosis and improves survival in sepsis. J Immunol 2004; 172: 7583-91.

[44] Parrino J, Hotchkiss RS, Bray M. Prevention of immune cell apoptosis as potential therapeutic strategy for severe infections. Emerg Infect Dis 2007; 13: 191-8.

[45] Schwulst SJ, Grayson MH, DiPasco PJ, et al. Agonistic monoclonal antibody against CD40 receptor decreases lymphocyte apoptosis and improves survival in sepsis. J Immunol 2006; 177 : 557-65.

[46] Weaver JG, Rouse MS, Steckelberg JM, Badley AD. Improved survival in experimental sepsis with an orally administered inhibitor of apoptosis. FASEB J 2004; 18: 1185-91.

[47] Sarkar A, Hall MW, Exline M, et al. Caspase-1 regulates Escherichia coli sepsis and splenic B cell apoptosis independently of interleukin-1beta and interleukin-18. Am J Respir Crit Care Med 2006; 174: 1003-10

[48] Hotchkiss RS, Tinsley KW, Swanson PE, et al. Sepsis-induced apoptosis causes progressive profound depletion of B and CD4+ T lymphocytes in humans. J Immunol. 2001; 166: 6952-63.

[49] Hotchkiss RS, Tinsley KW, Karl IE. Role of apoptotic cell death in sepsis. Scand J Infect Dis 2003; 35: 585-92.

[50] Le Tulzo Y, Pangault C, Gacouin A, et al. Early circulating lymphocyte apoptosis in human septic shock is associated with poor outcome. Shock 2002; 18: 487-94.

[51] Felmet KA, Hall MW, Clark RS, Jaffe R, Carcillo JA. Prolonged lymphopenia, lymphoid depletion, and hypoprolactinemia in children with nosocomial sepsis and multiple organ failure. J Immunol 2005; 174: 3765-72.

[52] Scumpia PO, Delano MJ, Kelly KM, et al. Increased natural $\mathrm{CD} 4+\mathrm{CD} 25+$ regulatory $\mathrm{T}$ cells and their suppressor activity do not 
contribute to mortality in murine polymicrobial sepsis. J Immunol 2006; 177: 7943-9.

[53] Wisnoski N, Chung CS, Chen Y, Huang X, Ayala A. The contribution of $\mathrm{CD} 4+\mathrm{CD} 25+$ T-regulatory-cells to immune suppression in sepsis. Shock 2007; 27: 251-7.

[54] Heuer JG, Zhang T, Zhao J, et al. Adoptive transfer of in vitrostimulated $\mathrm{CD} 4+\mathrm{CD} 25+$ regulatory $\mathrm{T}$ cells increases bacterial clearance and improves survival in polymicrobial sepsis. J Immunol 2005; 174: 7141-6.

[55] Scumpia PO, Delano MJ, Kelly-Scumpia KM, et al. Treatment with GITR agonistic antibody corrects adaptive immune dysfunction in sepsis. Blood 2007; 110: 3673-81.

[56] Monneret G, Debard AL, Venet F, et al. Marked elevation of human circulating $\mathrm{CD} 4+\mathrm{CD} 25+$ regulatory $\mathrm{T}$ cells in sepsisinduced immunoparalysis. Crit Care Med 2003; 31: 2068-71.
[57] Venet F, Pachot A, Debard AL, et al. Increased percentage of $\mathrm{CD} 4+\mathrm{CD} 25+$ regulatory $\mathrm{T}$ cells during septic shock is due to the decrease of CD4+CD25- lymphocytes. Crit Care Med 2004; 32: 2329-31.

[58] MacConmara MP, Maung AA, Fujimi S, et al. Increased CD4+ $\mathrm{CD} 25+\mathrm{T}$ regulatory cell activity in trauma patients depresses protective Th1 immunity. Ann Surg 2006; 244: 514-23.

[59] Chen X, Murakami T, Oppenheim JJ, Howard OM. Differential response of murine $\mathrm{CD} 4+\mathrm{CD} 25+$ and $\mathrm{CD} 4+\mathrm{CD} 25-\mathrm{T}$ cells to dexamethasone-induced cell death. Eur J Immunol 2004; 34: 85969.

[60] Fritzsching B, Oberle N, Eberhardt N, et al. In contrast to effector $\mathrm{T}$ cells, CD4+CD25+FoxP3+ regulatory $\mathrm{T}$ cells are highly susceptible to CD95 ligand- but not to TCR-mediated cell death. J Immunol 2005; 175: 32-6.

(C) Muszynski and Hall; Licensee Bentham Open.

This is an open access article licensed under the terms of the Creative Commons Attribution Non-Commercial License (http://creativecommons.org/licenses/by-nc/3.0/) which permits unrestricted, non-commercial use, distribution and reproduction in any medium, provided the work is properly cited. 